\title{
Life-Threatening Hemorrhage: \\ An Unusual Form of Presentation of Crohn's Disease Treated with Endoscopic Injection Sclerotherapy
}

Although rectal bleeding is a frequent symptom of inflammatory bowel disease, massive gastrointestinal hemorrhage has been described in only about $1 \%$ of patients with Crohn's disease (CD) (1-3). Nearly $90 \%$ of these cases require surgery, which is associated with a high mortality $(1-3)$. We report a case of a life-threatening hemorrhage as a form of presentation of $\mathrm{CD}$, which was successfully treated with endoscopic injection therapy.

A 55-year-old man was admitted to our Intensive Care Unit for massive rectal bleeding and hypovolemic shock. His medical history was unremarkable. The hematocrit at admission was $18 \%$ and 10 units of blood were transfused. After hemodynamic stabilization, a lower endoscopy showed inflammatory signs as well as aphthoid and serpiginous ulcers in the transverse and right colon, without active hemorrhage. However, an adherent red clot covering a visible vessel was present in a Crohn's ulcer (Figure 1). Injection therapy was performed with $3 \mathrm{ml}$ of $1 / 10000$ epinephrine and $5 \mathrm{ml}$ of $5 \%$ ethanolamine. Endoscopic biopsies confirmed the suspected diagnosis of $\mathrm{CD}$. Intravenous treatment with methylprednisolone was started, and the patient remained free of hemorrhage until discharge. No signs of rectal bleeding nor inflammatory activity were observed in subsequent out-patient controls.

Endoscopic injection sclerotherapy has proved to be a useful treatment for colorectal bleeding due to angiodysplasia (4) and varices (5). Massive bleeding may be the form of presentation of $\mathrm{CD}$. In this setting, lower endoscopy can suggest the diagnosis and also provide successful treatment of the hemorrhage, by means of injection sclerotherapy, thereby avoiding surgery.

M. Sans, J. Llach, J. M. Bordas, V. Andreu, A. Ginés, F. Mondelo, J. M. Piqué

Endoscopy Unit, Institut Clínic de Malalties Digestives,

Hospital Clínic I Provincial, Barcelona, Spain

\section{References}

1. Robert RJ, Sachar DB, Greenstein AJ. Severe gastrointestinal hemorrhage in Crohn's disease. Ann Surg 1991; 213: 207-11.

2. Cirocco WC, Reilly JC, Rusin LC. Life-threatening hemorrhage and exsanguination from Crohn's disease. Dis Colon Rectum 1995; 38: 85-95.

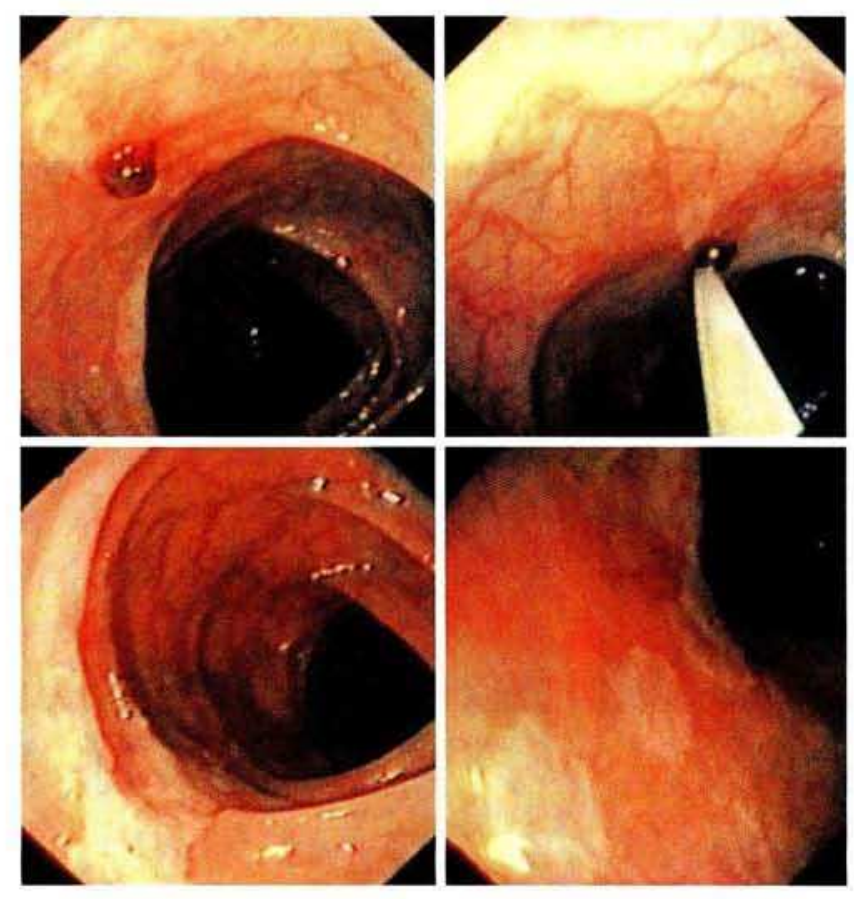

Figure 1: Red clot covering a visible vessel in a Crohn's disease ulcer, in the transverse colon. 
3. Driver CP, Anderson DN, Keenan RA. Massive intestinal bleeding in association with Crohn's disease. J R Coll Surg Edinb 1996; 41: 152-4.

4. Jaspersen D. Endoscopic Doppler in diagnosis and therapy of angiodysplasia. Endoscopy 1993; 25: 197.
5. Iwase H, Kyogane K, Suga S, Morise K. Endoscopic ultrasonography with color Doppler function in the diagnosis of rectal variceal bleeding. $\mathrm{J}$ Clin Gastroenterol 1994; 19: 227-30.
Corresponding Author Josep M. Bordas, M.D. Hospital Clínic

Villarroel 170

08036 Barceloná

Spain

Fax: +34-3541-6877 